\title{
Égypte-Europe, allers-retours
}

\section{Christophe Didier}

\section{(2) OpenEdition}

Journals

Édition électronique

URL : https://journals.openedition.org/rbnu/3300

DOI : $10.4000 /$ rbnu.3300

ISSN : 2679-6104

\section{Éditeur}

Bibliothèque nationale et universitaire de Strasbourg

\section{Édition imprimée}

Date de publication : 1 novembre 2010

Pagination : 6-7

ISSN : 2109-2761

\section{Référence électronique}

Christophe Didier, «Égypte-Europe, allers-retours », La Revue de la BNU [En ligne], 2 | 2010, mis en ligne le 01 novembre 2010, consulté le 08 août 2021. URL : http://journals.openedition.org/rbnu/3300 DOI : https://doi.org/10.4000/rbnu.3300

\section{(c) (i) (3)(2)}

La Revue de la BNU est mise à disposition selon les termes de la Licence Creative Commons Attribution - Pas d'Utilisation Commerciale - Partage dans les Mêmes Conditions 4.0 International. 


\section{LE DOSSIER \\ Egypte-Europe, allers-retours}

L'Égypte n'en finit pas d'exercer son attrait sur une Europe pour qui elle représente toujours un pan mystérieux de l'Orient. Voyageurs réels et imaginaires (on pense en France à quelques grands " orientalistes " comme Vivant Denon ou Gérard de Nerval) ont durablement contribué à la diffusion d'images d'autant plus tenaces qu'elles gardent aujourd'hui encore, du moins pour le grand public, une part d'ombre propre à stimuler toutes les curiosités, et parfois tous les fantasmes : le monde souterrain des momies et des trésors, les hiéroglyphes, l'aspect " exotique " que conserve en Europe l'organisation des sociétés musulmanes.

Cet attrait vieux de plusieurs siècles a suscité et nourri les recherches des archéologues, les interrogations des philologues, les pérégrinations des voyageurs et des artistes. De l'épopée napoléonienne à nos jours se sont succédé sans relâche publications, expositions et manifestations diverses qui se sont nourries, et continuent de se nourrir de la substance culturelle de l'ancien Égypte. Supports incontournables de ces recherches, les grandes collections dans les musées et les bibliothèques sont interrogées, étudiées sans trêve par des cercles parfois restreints mais toujours passionnés d'étudiants, d'enseignants et de chercheurs. Ce dossier ouvrira quelques portes sur ce qu'on pourrait appeler une " géographie de la recherche égyptologique ", ses réseaux, ses lieux d'attache, parmi lesquels Strasbourg occupe une place de choix.
De l'autre côté de la Méditerranée, la société égyptienne moderne interroge elle aussi les modèles occidentaux, et l'a fait ces dernières années d'une façon particulièrement originale, en ravivant elle aussi le passé et en reconstruisant, à Alexandrie, une grande bibliothèque. Cet édifice, vitrine de la culture égyptienne sur le monde, mais bâti par des architectes norvégiens et abritant dans ses magasins des collections francophones exceptionnelles, témoigne bien de ces incessants allers-retours entre Europe et Égypte, de cette fascination réciproque qui alimente les recherches et ouvre les civilisations les unes aux autres, dans un perpétuel jeu d'influences et d'enrichissements.

\section{Christophe Didier}

